\title{
Monaural ear differences for reaction times to speech with a many-to-one mapping paradigm
}

\author{
JOSÉ MORAIS \\ Laboratoire de Psychologie expérimentale, Université libre de Bruxelles, B-1050 Brussels, Belgium
}

\begin{abstract}
On each trial, subjects were presented monaurally with single synthetic speech syllables. In Experiment I, when /ba/ and / ta/ specified one response, and $/ \mathrm{da} /$ and $/ \mathrm{ka} /$ another response, a right-ear advantage in reaction time was observed; when /ba/ specified one response and all the other stimuli specified the other response, no ear effect was observed. Unsuccessful attempts to obtain a monaural right-ear advantage for consonants in some reaction-time tasks might be due to some kind of prephonetic matching between a representation of the stimulus attended to and the presented stimulus, the output of this match providing sufficient information for response. In Experiment II, /bi/ and /b $\mathrm{J} /$ specified one response and $/ \mathrm{b} \varepsilon /$ and $/ \mathrm{bu}$ / the other response, but no ear effect was observed. It was concluded that the right-ear advantage displayed for consonants in the corresponding condition of Experiment I was not the pure effect of a particular stimulus-response mapping, but depended also on the phonetic properties of consonants.
\end{abstract}

For some years after the classic demonstration by Kimura (1961) of a right-ear advantage in the recall of dichotically presented lists of digits, dichotic presentation has been thought to be a necessary requisite for the occurrence of the effect. In fact, neither with monaural presentation of filtered speech (Calearo \& Antonelli, 1963) nor with digits alternating rapidly between ears (Kimura, 1967) were right-ear advantages obtained. Since 1970, several reports of monaural ear effects for verbal material have appeared, but in conditions where short-term memory was probably a determinant factor. For series of letters presented monaurally, Bakker (1969) found right-ear advantage when recall of their order was required and not under a free recall situation. Bever (1971), Frankfurter and Honeck (1973), and Jarvella and Herman (1973) reported right-ear advantages in recall of monaurally presented sentences tested after an interpolated task.

Using a perceptual task and reaction time as a measure, Springer (1973) reported right-ear advantage for speech presented to one ear only provided that the opposite ear received a burst of white noise. In that experiment, one CV syllable-noise pair was presented on each trial, with the syllables occurring in a given block all presented to the same ear. The syllable $/ \mathrm{ba} /$ occurred with a probability of .50 in each block of 40 trials, and each of the remaining syllables, $/ \mathrm{da} /, / \mathrm{ga} /, / \mathrm{pa} /, / \mathrm{ta} /, / \mathrm{ka} /$, with a probability of .10 . The task was to decide on each trial whether /ba/ occurred or not. The mean

This work was partially subsidized by the Belgian "Fonds de la Recherche fondamentale collective" under Contract No. 10.152. Requests for reprints should be sent to José Morais, Laboratoire de Psychologie expérimentale. Av. Adolphe Buyl, 117-1050 Bruxelles. Belgium. reaction time to right-ear items was $15 \mathrm{msec}$ faster than to left-ear items, and no interaction effect between ear and type of decision was noticed. With the same paradigm and identical stimuli but in the absence of contralateral noise, Springer observed just a slight and nonsignificant difference $(3 \mathrm{msec})$ favoring the left ear. A more recent experiment by Morais and Darwin (1974) has shown right-ear advantage under monaural stimulation on a task involving a simple phonetic judgment. The subjects heard sequences of two $\mathrm{CV}$ syllables which they had to judge in terms of "same" or "different." The first syllable was always presented binaurally; the second came either to the left or to the right ear with no concurrent stimulation in the opposite ear. The subjects were faster $(16 \mathrm{msec})$ in judging the syllables "different" when the second syllable came to the right ear than when it came to the left, but there was no ear difference for "same" judgments. These results have since been replicated by Morais (1975) with a similar procedure but no ear uncertainty.

The apparent contradiction between the ear difference observed by Morais and Darwin (1974) and the symmetry in the absence of contralateral noise observed by Springer (1973) may be accounted for in at least two ways. The first way is to attribute the responsibility for the appearance of an ear difference in the "same-different" experiment to the need to remember one syllable in order to compare it with the second. The other way is to assume that Springer's subjects, confronted with a yes/no decision, behaved in a manner similar to that of Morais and Darwin's subjects when they were responding to the "same" pairs. It is commonly supposed that "same" judgments can be arrived at on the basis of some matching operation; lack of a higher level, categorical process might explain why they failed to show left-hemisphere 
specialization for "same" judgments. In Springer's situation, a useful strategy for the subject might be to generate some pattern of the syllable /ba/ (which occurred five times more frequently than each of the other syllables and did not share its associated response with any other stimulus) in order to compare it with the representation of the syllable presented on the trial. If the match were positive, no categorical process would be needed; if it were negative, the response would be triggered by exclusion, thus avoiding full identification of the stimulus. In either case, no ear difference would be observed. But then one might wonder why the subjects do not make use of a response by exclusion for the "different" pairs in the "same-different" paradigm, for which they seem, in stead, to engage the superior capabilities of the left hemisphere. Perhaps an independent process of feature comparison of two successively presented stimuli leads to the detection of a difference and, consequently, to a "different" decision in a time which is shorter than the time needed to perform an unsuccessful match and interpret this failure.

The aim of Experiment I was twofold: (1) to test the hypothesis that right-ear advantage for reaction times to monaurally presented speech may be observed under conditions where no memory for a previous event is required; and (2) to demonstrate that the effect observed in these circumstances may disappear under conditions where (a) selective preparation to a particular stimulus-response pair is favored, and (b) all the information needed for the response may be given by a single matching operation.

\section{EXPERIMENT I}

The subjects were presented monaurally with only one speech stimulus, out of a set of four, on each trial. In one condition, each stimulus occurred with a .25 probability and a different response was associated with each group of two stimuli. The assignment of the syllables to the two responses was such that the subject could not distinguish the two sets of stimuli on the basis of a single acoustic cue. Right-ear advantage was predicted in that condition. In the other condition, one of the four stimuli occurred with a .50 probability and was associated alone with one response; the other three shared evenly the remaining probability and were associated with the other response. As selective preparation to the more frequent and univocal stimulus-response pair was probably systematic, and as a matching strategy would be sufficiently informative for the demands of the task, no ear difference would be predicted in the latter condition.

\section{Method}

Subjects. Eight right-handed students, with no known history of hearing disorder, were used as subjects; two were male and six female, with an age range of 16-28 years. Each was tested individually in a quiet room for six 30 -min sessions, which were run in groups of three on 2 successive days. They were paid a fixed rate per session, plus bonus and penalties depending on speed and accuracy, as described later.

Stimuli. Four synthetic speech consonant-vowel (CV) syllables lasting 300 msec were used in Experiment I: $/ \mathrm{ba} /, / \mathrm{ta} /, / \mathrm{da} /$, $/ \mathrm{ka} /$. Like Morais and Darwin's (1974) stimuli, they have been prepared with a parallel formant speech synthesis program on the Elliott 4130 computer at the University of Sussex. Two experimental tapes were constructed: on one tape, each syllable was recorded 25 times; on the other tape, the syllable /ba/ was recorded 50 times and the other syllables were recorded 16 or 17 times each, also for a total of 50 . On each tape, all 100 trials were randomized. All syllables were recorded on one track only, the same cross each tape. The sounds were delivered over Sharp HA-10 headphones from a Revox A77 stereophonic tape recorder.

Procedure. The subject was seated at a table, on which there was a two-way switch which the subject held between the thumb and the index finger of the responding hand. His responding forearm rested on the table. He was told that every $5 \mathrm{sec}$ he would hear one syllable which would be presented at one ear only across each block of trials (25 trials).

Each subject performed under two conditions: in condition "2-1, 2-1" (two stimuli/one response, two stimuli/one response), the tape on which all stimuli occurred with equal probability was used, and the subjects were instructed to move the switch away from their bodies as quickly as possible if they had heard /ba/ or $/ \mathrm{ta} /$ and towards their bodies if they had heard $/ \mathrm{da} /$ or $/ \mathrm{ka} /$. In condition "1-1, 3-1" (one stimulus/one response, three stimuli/one response), the tape in which $/ \mathrm{ba} /$ was three times as frequent as each of the other syllables was used, and the subjects were instructed to move the switch away from their bodies if they had heard /ba/ and towards their bodies if they had heard /ta/ or /da/ or $/ \mathbf{k a} /$.

For one-half of the subjects, Sessions 1,2, and 3 were devoted to condition "2-1, 2-1," and Sessions 4, 5, and 6 to condition "1-1, 3-1." This assignment was reversed for the other half of the subjects. Sessions 1 and 4 were devoted to training and were discarded from the analysis. Each session, during which the appropriate tape was played two times, had eight blocks of 25 trials. A rest pause was allowed after the fourth block. Subjects changed hand of response after the first, third, fifth, and seventh block in each session; the order in which they used the left and the right hand was counterbalanced both within-subject (for instance, RLLRRLLR in Experimental Sessions 2 and 5, LRRLLRRL in Experimental Sessions 3 and 6) and across subjects. Head phones were reversed after a block, and their position on the head was again counterbalanced both within-subject (for instance, RLRLRLRL in Experimental Sessions 2 and 5, LRLRLRLR in Experimental Sessions 3 and 6 ) and across subjects. Thus, in each session, each responding hand by ear combination was used the same number of times. Within each group of four subjects receiving a different order of conditions, " $2-1,2-1$ " and " $1-1$, 3-1," each subject had a different combination of hand order with ear sequence.

An electronic timer (Advance TC-12 Timer-Counter) connected to a voice key, which was fed to the output channel of the tape recorder that was delivering the stimuli, measured the time from syllable onset to response. After each response, the subject was told whether he had been "fast" or "slow," meaning faster or slower than the mean correct RT on the previous session. After an error, the subject was told of it and no information regarding speed was given. For each fast RT the subject was awarded 0.5 Belgian franc (approximately US 1.5 cents; for each error. 1 franc was deducted. All subjects were told of their gains immediately after each experimental block.

\section{Results}

Mean correct RTs (in milliseconds), standard deviations (SD), and percent errors, by condition and by ear for all subjects, are shown in Table 1 . A four-way analysis of variance, including ear, hand, 
Table 1

Mean Correct RTs (in Milliseconds), Standard Deviations (SD), and Percentage Errors by Condition and by Ear for All Subjects

\begin{tabular}{|c|c|c|c|c|c|c|c|c|c|c|c|c|}
\hline \multirow[b]{3}{*}{ Subject } & \multicolumn{6}{|c|}{ Condition 2-1, 2-1 } & \multicolumn{6}{|c|}{ Condition 1-1, 3-1 } \\
\hline & \multicolumn{3}{|c|}{ Left } & \multicolumn{3}{|c|}{ Right } & \multicolumn{3}{|c|}{ Left } & \multicolumn{3}{|c|}{ Right } \\
\hline & $\begin{array}{l}\text { Mean } \\
\text { RT }\end{array}$ & $\mathrm{SD}$ & $\begin{array}{c}\text { Errors } \\
\%\end{array}$ & $\begin{array}{c}\text { Mean } \\
\text { RT }\end{array}$ & $\mathrm{SD}$ & $\begin{array}{c}\text { Errors } \\
\%\end{array}$ & $\begin{array}{c}\text { Mean } \\
\text { RT }\end{array}$ & SD & $\begin{array}{c}\text { Errors } \\
\%\end{array}$ & $\begin{array}{l}\text { Mean } \\
\text { RT }\end{array}$ & SD & $\begin{array}{c}\text { Errors } \\
\%\end{array}$ \\
\hline $\begin{array}{l}1 \\
2 \\
3 \\
4 \\
5 \\
6 \\
7 \\
8\end{array}$ & $\begin{array}{l}485 \\
548 \\
412 \\
502 \\
413 \\
395 \\
425 \\
539\end{array}$ & $\begin{array}{r}97 \\
111 \\
106 \\
135 \\
114 \\
132 \\
149 \\
106\end{array}$ & $\begin{array}{r}5.5 \\
4.5 \\
5.0 \\
8.0 \\
6.5 \\
8.0 \\
12.5 \\
6.5\end{array}$ & $\begin{array}{l}472 \\
533 \\
400 \\
485 \\
420 \\
389 \\
402 \\
499\end{array}$ & $\begin{array}{r}111 \\
111 \\
91 \\
121 \\
100 \\
119 \\
137 \\
85\end{array}$ & $\begin{array}{r}3.5 \\
7.5 \\
4.5 \\
3.5 \\
3.5 \\
11.0 \\
10.5 \\
8.0\end{array}$ & $\begin{array}{l}374 \\
354 \\
293 \\
368 \\
347 \\
308 \\
391 \\
354\end{array}$ & $\begin{array}{r}86 \\
74 \\
72 \\
88 \\
82 \\
85 \\
107 \\
70\end{array}$ & $\begin{array}{r}.5 \\
5.5 \\
6.5 \\
3.0 \\
4.0 \\
2.0 \\
7.5 \\
7.0\end{array}$ & $\begin{array}{l}382 \\
342 \\
286 \\
360 \\
339 \\
322 \\
381 \\
365\end{array}$ & $\begin{array}{r}96 \\
75 \\
63 \\
83 \\
83 \\
86 \\
103 \\
74\end{array}$ & $\begin{array}{r}2.0 \\
4.0 \\
5.5 \\
5.5 \\
5.0 \\
9.0 \\
11.0 \\
7.0\end{array}$ \\
\hline Mean & 465 & 119 & 7.1 & 450 & 109 & 6.5 & 349 & 83 & 4.5 & 347 & 83 & 6.1 \\
\hline
\end{tabular}

condition, and subject, was performed on the mean RT data. The ear effect was significant at $p<.05$ $[F(1.7)=6.26]$. Since the Ear by Condition interaction $[F(1,7)=4.80]$ was not very far from significance at $p<.05$, two separate three-way analyses of variance were performed, one for condition "2-1, 2-1," the other for condition " $1-1$, $3-1$." In condition "2-1, 2-1," the ear effect was significant at $p<.025[F(1,7)=9.49]$; subjects responded on average $15 \mathrm{msec}$ faster to syllables presented at the right ear than to syllables presented at the left ear. In condition "1-1, 3-1," there was no ear effect $[F(1,7)<1]$. Neither hand nor Hand by Ear were significant in either condition. A one-tailed $t$ test comparing the two conditions for the difference in ear differences showed a significant effect $[t(7)=1.99$, $p<.05]$. Further analysis of condition "1-1, 3-1" showed the absence of an ear effect for both responses; responses to the right ear were only slightly faster than those to the left, by 2.75 and $0.75 \mathrm{msec}$ for $/ \mathrm{ba} /$ and for $/ \mathrm{da} /, / \mathrm{ta} /, / \mathrm{ka} /$, respectively. In this condition, / ba/ responses were on average $25 \mathrm{msec}$ faster than responses to the other syllables, a difference which was significant at $\mathrm{p}<.005[\mathrm{t}(7)=$ 3.85]. No significant ear difference was observed in percentage of errors in either condition.

\section{Discussion}

The finding of a monaural right-ear advantage in reaction times to $C V$ syllables in a two-to-one stimulus-response paradigm supports the view that the occurrence of a monaural ear difference for speech is not dependent on some involvement of auditory memory going beyond immediate processing of the stimulus. On the other hand, the fact that the same subjects showed no effect with a paradigm in which the most frequent of four stimuli was associated alone to one of two responses suggests that Springer's (1973) failure to demonstrate a monaural ear effect in the absence of contralateral noise may be peculiar to procedures which favor selective preparation and in that way encourage a matching strategy. When the task is such that a negative output to the match does not permit a decision (this would be the case in our condition " $2-1,2-1 ")$, phonetic processing leading to full identification of each speech signal would be needed, resulting in a right-ear advantage.

It might be objected, however, against this interpretation that an ear difference arose in condition "2-1, 2-1," not because of the particular kind of stimulus processing, but because the stimuli were arranged in two arbitrary categories not concerned specifically with phonetic processing. This objection was checked in Experiment II by using the two-to-one stimulus-response paradigm with $\mathrm{CV}$ syllables differing in the vowel. It is known that vowels do not elicit significant right-ear advantage, except under special conditions (see Darwin, 1974, for a discussion). They should, however, elicit an ear difference under the "2-1, 2-1" condition if the effect observed for consonants in the same situation were just a consequence of attributing a set of stimuli to each response.

\section{EXPERIMENT II}

Experiment II used the "2-1, 2-1" condition alone, and the stimuli were four syllables differing in the vowel. The assignment of the syllables to the two responses was such that the subjects could not distinguish the two sets of stimuli on the basis of a simple dichotomy on the frequency scale for either the first or the second formant position.

\section{Method}

Subjects. Eight right-handed students, with no known history of hearing disorder, were used as subjects; four of them had been used in Experiment $I$, in which they showed right-ear advantages for condition "2-1, 2-1" (Subjects 1, 2, 3, and 4 in Table 1). Three were male and five female, with an age range of 16-26. Each was tested individually for three 30-min sessions, which were run on the same day. They were paid as in Experiment $I$.

Stimuli and Procedure. Four synthetic speech CV syllables lasting $300 \mathrm{msec}$ and prepared at the University of Sussex were used in Experiment II: $/ \mathrm{bu} /, / \mathrm{b} \varepsilon /, / \mathrm{bi} /, / \mathrm{b} \supset /$. The experimental tape was constructed according to the same principle of the "2-1, 2-1" 
tape of Experiment 1. The procedure employed here replicated exactly that of Experiment I relative to condition "2-1, 2-1." The subjects were instructed to move the switch away from their bodies if they had heard / bi/ or /b $ว /$ and toward their bodies if they had heard $/ \mathrm{bu} /$ or $/ \mathrm{bc} /$. The group of subjects previously used and the new group were identical regarding the way in which the order of ear and of responding hand were counterbalanced.

\section{Results}

The mean RTs for the left and the right ear were 469.5 and $471.1 \mathrm{msec}$, respectively. Three subjects showed faster RTs for the right ear than for the left $(1,6$, and $11 \mathrm{msec})$, four subjects the reverse $(3,5,8$, and $15 \mathrm{msec}$ ), and one subject showed no difference. The mean ear differences of the old and new subjects were, respectively, 0.25 and $3 \mathrm{msec}$, favoring the left ear. Percent of errors was $4.8 \%$ and $4.1 \%$, respectively, for the left and the right ear.

These results clearly showed the absence of a monaural ear effect in reaction times to $\mathrm{CV}$ syllables differing in the vowel. Although accepting the null hypothesis is dangerous, it may be argued against this criticism that the absence of effect was observed even for the group of subjects who displayed a right-ear advantage for consonants in the corresponding condition of Experiment I. The result of Experiment I was thus giving evidence of the specialization of the left hemisphere in decoding consonants, rather than being a mere product of a particular stimulus-response arrangement.

\section{GENERAL DISCUSSION}

Since the experimental work reported here was done, and besides the Morais and Darwin (1974) experiment, several reports of monaural ear effects in reaction times to speech have been published (Cohen \& Martin, 1975; Fry, 1974) or are about to be published (Bever, Hurtig, \& Handel, in press). The amount of evidence in favor of a monaural right-ear advantage under conditions where no effect of memory factors can be invoked reasonably is now considerable. Some of these findings, together with a failure to obtain monaural ear differences (Stevenson, 1973), will be discussed here in connection with the interpretation outlined above for the difference observed between the two conditions of Experiment I.

In Fry (1974), the subjects were presented monaurally with one of two speech stimuli and choice reaction time was measured. Different pairs were used in different series of trials: /bit-bet/, / pit-bit/, /lei-rei/, and /splei-sprei/. Significant right-ear advantage was found for the last two pairs (15 and 25 msec, respectively) and nonsignificant ones for the first two (4 and $6 \mathrm{msec}$, respectively). Let us note that the strategy of generating a prephonetic representation for a matching operation (if it really takes place) may be, in theory, as useful in a two-choice reaction time task with monaurally presented stimuli each of .5 probability as in a mapping paradigm of the type of the "1-1, 3-1" condition of Experiment I. The effects observed for /lei-rei/ and/splei-sprei/, contrasting with the absence of asymmetry for /pit-bit/, might suggest that the possibility of using a matching strategy depends on the particular acoustic cues which carry the distinction between the stimuli. A tentative account of Fry's results would be that the time relation of the onset of voicing and the burst of noise occasioned by the release of the plosive conspnant in the /pit-bit/ pair provides a more distinctive gue for a mismatch than the transitions of the second and the third formants in the other two pairs.

Using pairs of CVC words contrasting in the initial consonant, the vowel, or the final consonant, Stevenson (1973) found no significant ear differences in reaction time, whatever the position of the contrast was. On each trial, the subjects were first visually presented with two printed words; $3 \mathrm{sec}$ later, they were monaurally presented with one of them, and they had to press a corresponding response button. It must be noted that on a large proportion of trials the members of the pair were very different acoustically from each other. In particular, in the consonantcontrasting series, two affricate consonants were used, $/ \mathrm{dz} /$ and $/ \mathrm{t} \int /$, besides the six usual stop consonants, and more than $40 \%$ of the trials consisted of an affricate-stop pair. Furthermore, the pairs differing more widely in acoustic properties were put essentially at the beginning of the test. This may have strongly induced a strategy of matching of the presented stimulus with an internal auditory (prephonetic) representation.

More recently, Bever, Hurtig, and Handel (in press) have found right-ear advantage in recognizing the phoneme target $/ b /$ in a list of monaurally presented CVC syllables, but none in recognizing an entire syllable. Listening for a target is of course a situation where selective preparation reaches a maximum. Even if an auditory image of a syllable can be matched with the auditory representation of the stimulus presented to the subject, as for /b/ there is no auditory representation independent of any context an image of $/ b /$ in a particular context would miss the target most of the time. When listening for $/ b /$, subjects would then be obliged to carry out phonetic analysis. However, when listening for $/ b /$ in a constant context, as was probably the case in condition " $1-1,3-1$ " of the present work (Experiment I), subjects would be in similar conditions to listening for a syllable (in the occurrence $/ \mathrm{ba} /$ ) and some kind of matching operation would become possible.

It seems that one might summarize the data reported by Bever, Hurtig, and Handel (in press), Fry (1974), Morais and Darwin (1974), Springer (1973), Stevenson (1973), and in Experiment I of the present work as meaning that every time the subject can deal 
with speech only at its auditory (prephonetic) level in order to respond, no right-ear advantage effect occurs. Right-ear advantage occurs when phonetic analysis intervenes. As Bever and collaborators claim, and we agree, finding a monaural ear effect in speech perception is a matter of the task and of the kind of processing this task suggests or imposes to the subjects. In dichotic experiments, or when speech is opposed by noise, the auditory representation of the speech stimulus would not be "clear" enough to dispense phonetic analysis. The auditory (prephonetic) representation would also cease to be useful when the acoustic properties of the stimuli are less well reproduced (as would be the case for some pairs used in Fry, 1974) or when an independent phonetic process of feature extraction may be faster than interpreting a mismatch (as would be the case for the "different" judgments in Morais and Darwin, 1974). On the other hand, the fact that right-ear advantage was observed in condition "2-1, 2-1" of Experiment I suggests that no more than one stimulus may have a prephonetic representation in a selective attention stage. In fact. if the subjects could perform in parallel two matching operations on the presented stimulus with the images of $/ \mathrm{ba} /$ and $/ \mathrm{ta} /$, they would have information enough to take a decision without further processing.

The two-to-one stimulus-response mapping paradigm offers the possibility of investigating whether or not acoustic parameters underlying phonetic contrasts can be independently represented for prephonetic matching. In the present study, a difference on a single acoustic cue would not provide sufficient information for deciding about the response. A voiced and an unvoiced stop were included in each pair of stimuli associated to one response, and the two dental stops were associated to different responses. But we might have a different distribution of the syllables, for instance /ba/ and /da/ vs. /ta/ and $/ \mathrm{ka} /$, or $/ \mathrm{da} /$ and $/ \mathrm{ta} / \mathrm{vs}$. $/ \mathrm{ba} /$ and $/ \mathrm{ka} /$. The possibility of generating an auditory (prephonetic) representation containing just the acoustic cues critical for the choice of the response (for instance, a particular time relation in the onset of the formants, but not a particular form of the transitions of the second and third formants) could be tested by manipulating the distribution of syllables in this paradigm.

\section{REFERENCES}

BAKKER, D. Ear asymmetry with monaural stimulation: Task influences. Cortex, 1969, 5, 36-42.

BeVER, T. G. The nature of cerebral dominance in speech behavior of the child and adult. In R. Huxley \& E. Ingram (Eds.), Mechanisms of language development. New York: Academic Press, 1971.

Bever, T. G., Hurtig, R. R., \& Handel, A. B. Analytic processing elicits right ear superiority in monaurally presented speech. Neuropsychologia, in press.

Calearo, C., \& Antonelli, A. R. "Cortical" hearing tests and cerebral dominance. Acta Oto-Laryngologica, 1963, 56, 17.26.

Cohen, G., \& Martin, M. Hemisphere differences in an auditory Stroop test. Perception \& Psychophysics, 1975, 17, 79-83.

DARWIN, C. J. Ear differences and hemispheric specialization. In F. O. Schmitt \& F. G. Worden (Eds.), The neurosciences. Third study program. Cambridge Mass: M.I.T. Press, 1974.

Frankfurter, A., \& Honeck, R. P. Ear differences in the recall of monaurally presented sentences. Quarterly Joumal of Experimental Psychology, 1973, 25, 138-146.

FRY, D. B. Right ear advantage for speech presented monaurally. Language and Speech, 1974, 17, 142-151.

Jarvella, R. J., \& Herman, S. J. Speed and accuracy of sentence recall: Effects of ear presentation, semantics and grammar. Joumal of Experimental Psychology, 1973, 79, 111-113.

KimuRA, D. Cerebral dominance and the perception of verbal stimuli. Canadian Journal of Psychology, 1961, 15, 166-171.

KimurA, D. Functional asymmetry of the brain in dichotic listening. Cortex, 1967, 3. 163-178.

MoraIs, J. Monaural ear differences for same-different reaction times to speech with prior knowledge of ear stimulated. Perceptual and Motor Skills, 1975, 41, 829-830.

MoraIs, J., \& DARWIN, C. J. Ear differences for same-different reaction times to monaurally presented speech. Brain and Language, 1974, 1, 383-390.

SPRINGER, S. Hemispheric specialization for speech opposed by contralateral noise. Perception \& Psychophysics, 1973, 13, 391-393.

Stevenson, P. W. Reaction time measurements in speech discrimination tasks-an automated system with closed responses. Journal of Phonetics, 1973, 1, 347-367.

(Received for publication July 14, 1975; revision accepted November 3,1975 .) 